\title{
PSICOPEDAGOGIA E O ALUNO COM TRANSTORNO DE ESPECTRO AUTISTA - TEA ${ }^{1}$ \\ PSYCHOPEDAGOGY AND THE STUDENT WITH AUTISTIC SPECTRUM DISORDER - TEA
}

\section{Carine Michelon de Oliveira ${ }^{2}$}

\section{RESUMO}

A pesquisa bibliográfica situou-se no assunto relativo ao trabalho do psicopedagogo com crianças que apresentam Transtorno de Espectro Autista - TEA no ambiente escolar, situando características da criança - TEA que dificultam sua aprendizagem do modo convencional ofertado pelo ensino curricular. De maneira que o psicopedagogo em sua atuação fornecerá vínculos, subsídios e formas para que esse aluno não seja excluído e que adquira conhecimento educacional, levando em conta as necessidades e limitações do próprio transtorno de espectro autista - TEA. O trabalho psicopedagogico é realizado com um todo, desde educadores, e família, para que assim consiga ter maior resultado positivo no acompanhamento deste aluno. A pesquisa objetivou trazer em suma a importância da profissão para o êxito de alunos muitas vezes vistos como inaptos para o ensino escolar.

Palavras-chave: Psicopedagogo. Autista. Aluno.

\section{ABSTRACT}

The bibliographic research was located on the subject related to the work of the psychopedagogue with children who have Autistic Spectrum Disorder - ASD in the school environment, situating characteristics of the child - ASD that hinder their learning in the conventional way offered by curricular teaching. In such a way that the psychopedagogue in his / her performance will provide bonds, subsidies and ways so that this student is not excluded and that he / she acquires educational knowledge, taking into account the needs and limitations of the autistic spectrum disorder - TEA. The psychopedagogical work is carried out with a whole, from educators, and family, so that it can have a greater positive result in the monitoring of this student. The research aimed to bring in short the importance of the profession for the success of students often seen as unfit for school education.

Keywords: Psicopedagogo. Autistic. Student.

\footnotetext{
1 Artigo de pesquisa.

2 Graduada em psicologia pela Faculdade Integrada de Santa Maria-RS, pós-graduada em neuropsicologia pelo Instituto Tecnológico Pró-Minas e pós-graduanda em psicopedagogia pela Faculdade Dom Alberto-RS, e-mail: carineif@hotmail.com
} 


\section{INTRODUÇÃO}

A proposta de pesquisa condiz com um assunto relevante e freqüente nas escolas públicas e privadas tanto quanto nas clinicas de psicopedagogia, referente ao ensino e aprendizagem da criança com Transtorno de Espectro Autista TEA, o aluno autista trás consigo peculiaridades e em muitos casos dificuldades de aprender do modo convencional em sala de aula, dificuldades estas, refletidas quando comparadas com alunos tidos como "normas", ou seja, que não apresentam o Transtorno de Espectro Autista e demais peculiaridades.

A psicopedagogia equivale a auxiliar aquele aluno que não aderi ao meio imposto por muitos professores para ensinar em sala de aula, o psicopedagogo na sua arte de trabalhar traz meios e formas distintas de conduzir esse aluno visto como o "aluno que possui problemas de aprendizagem", compreendendo o seu perfil singular de aprender que muitas vezes é até visto como o incapaz de compreender conteúdos, material didático e outros equivalentes do ensino educacional. No decorrer dos anos observou-se que o aluno "atrasado" no aprender dentro da sala de aula, também possui capacidades e potencialidades, mesmo apresentando limitações cognitivas e comportamentais, devido a TEA.

O trabalho do psicopedagogo é fundamental em muitas áreas e dificuldades de aprendizagem, contudo a pesquisa apresenta de modo particular o profissional de psicopedagogia no contexto escolar da criança com Transtorno de Espectro Autista - TEA, relativo às principais dificuldades e limitações dessa criança. Assim como outros transtornos, o autista representa uma parcela de indivíduos com características decorrentes da sua condição, refletidas dentro do ambiente escolar, o psicopedagogo preparado para exercer sua função no ensino do aluno autista, devera conhecer as condições de cada aluno, pois existem graus e características diferentes em cada criança, o profissional de psicopedagogia necessita entrar no mundo individual de cada criança e compreender a melhor técnica e maneira de ensinar para que a criança consiga entender e aprender da melhor forma possível.

Com esta pesquisa objetivou-se conhecer o quanto é importante e essencial o trabalho psicopedagogico na educação escolar de crianças autistas. Compreender as principais limitações que esse aluno apresenta e contribuições do psicopedagogo no contexto escolar e institucional no trabalho com alunos autistas. Crianças diagnosticadas com Transtorno de Espectro Autista - TEA representam desafios para os pais e comunidade envolvida, porém com profissionais qualificados e conhecimento a respeito das características do transtorno, contribuirão para minimizar os desafios encontrados em todos os momentos e ambientes no qual este aluno está inserido, e na educação não será diferente.

A relevância no presente trabalho acadêmico tem o intuito de ajudar no propósito de ser possível trabalhar de forma segura, precisa e contribuinte na educação e vida dessas crianças, em decorrência de profissionais da psicopedagogia que auxiliem na formação educacional desses alunos que na maioria das vezes, são vistos como incapazes. Para o desenvolvimento deste trabalho foi realizada uma pesquisa bibliográfica exploratória, não sistemática, que se constitui em ser um levantamento 
de referências bibliográficas, publicadas em meios escritos e eletrônicos, artigos científicos, páginas de web sites, auxiliando o pesquisador a conhecer o que já se pesquisou sobre determinada temática.

\section{REFERENCIAL TEÓRICO}

Foi na França que as ideias iniciais de psicopedagogia surgiram na década de 40, médicos e educadores visavam compreender e solucionar as dificuldades de aprendizagem de forma fisiológica e pedagógica (PERES, 1998). Sendo em Paris que nasceu o $1^{\circ}$ Centro psicopedagogico, tratando das crianças que apresentavam problemas escolares, ou seja, de aprendizagem (PERES, 1998). As primeiras iniciativas do trabalho psicopedagogico no Brasil surgiram nos anos 60, devido ao grande número de evasão escolar e fracasso neste mesmo contexto (PERES, 1998).

Mas afinal o que é psicopedagogia? O mesmo condiz com uma área cientifica de conhecimento, que auxilia na compreensão da aprendizagem humana, trabalho mediado entre sujeito, família e escola, dessa forma o trabalho psicopedagogico é desafiador na medida em que se depara com atuação em transformar a educação (QUEIROZ, 1990). Neste âmbito encontramos a intervenção clinica e institucional, a psicopedagogia clínica é de forma individual e terapêutica, onde as escolas e família encaminham os alunos com alguma dificuldade para fazer acompanhamento com o psicopedagogo e equipes interdisciplinar, como médicos, fonoaudiólogos, psicólogos, dentre outros. No âmbito institucional, também acontece em equipe interdisciplinar, desta vez com professores, coordenadores pedagógicos, diretores e outros envolvidos, de forma a auxiliar na prevenção das dificuldades e solucionar as existentes (QUEIROZ, 1990).

\footnotetext{
A Psicopedagogia é um campo de atuação em Saúde e Educação que lida com o processo de aprendizagem humana: seus padrões normais e patológicos considerando a influência do meio - família, escola e sociedade - no seu desenvolvimento, utilizando procedimentos próprios da Psicopedagogia" ( $A B P P)$. O autismo é um transtorno do desenvolvimento cujo tratamento é essencialmente psicoeducacional, assim, esse profissional contribui muito para o aprimoramento das habilidades necessárias ao desenvolvimento da pessoa que se encontra dentro do espectro do autismo (BATISTA; VIEIRA, p. 14. 2015).
}

Sendo assim compreende-se a importância de profissionais psicopedagogos institucionais e nas clinicas no trabalho com crianças que apresentam prejuízos na aprendizagem, o Transtorno de Espectro Autista - TEA é um dos casos pelo qual se precisa do acompanhamento desse profissional para que o aluno consiga de forma mais efetiva possível adquirir aprendizagem escolar. O Transtorno de Espectro Autista - TEA é reconhecido como deficiência desde o ano de 2012, trazendo algumas características peculiares do transtorno como: distanciamento e falta de interação social, agir de forma atípica no ambiente escolar e outros, dos demais alunos não autistas, dificuldades em assimilação e falta de interesse em determinados conteúdos, dificuldade de manter contato visual e de compreender o que ouve, além de repetição de palavras e frases, movimentos estereotipados, comprometimentos na 
esfera motora, dentre outros comportamentos que podem dificultar ainda mais a convivência e acomodação de matérias didáticos e até mesmo os comportamentos em sala de aula (DINIZ; SANTOS, 2018).

Integrando o Manual Diagnóstico e Estatístico de Transtornos Mentais, DSM-V (2013), como um Transtorno do Neurodesenvolvimento, o TEA não possui padrões fixos para sua manifestação, apresentando grande variedade de sintomas. Suas principais características incluem os prejuízos na comunicação e consequentemente na interação social, e padrões restritivos e repetitivos de comportamentos que se iniciam logo nos primeiros anos de vida do sujeito. Também pode apresentar, ou não, algum grau de Deficiência Intelectual (NASCIMENTO; SOUZA, 2018, p. 170).

No entanto atender ao aluno autista requer muitas mudanças, desafios, proposta de trabalho especifica, tanto de profissionais como de matérias e espaços ofertados na escola e ou clínica de atendimento, seguindo o perfil e se adequando a cada ponto significativo do aluno, buscando aprofundar-se cada vez mais na problemática que ele demanda (SILVA; GAIATO; REVELES, 2012). O psicopedagogo precisa aprimorar a relação com o outro, atividades, comunicação verbal e não verbal, para que assim possa estimular a atenção e interação do aluno autista, evitar passar apenas conteúdos escolares corriqueiros e socialmente valorizados como apresentados de costume para a classe escolar, mas conciliando com dramatizações muito significativas para autistas, variações de linguagens, de forma que possa proporcionar aperfeiçoamento psicológico e cognitivo (SILVA; GAIATO; REVELES, 2012). O reforçamento positivo é uma técnica muito utilizada, equivalente a inserir um estimulo diante de um comportamento adequado por parte da criança, os estímulos variam de situações, eles podem ser elogios, relativos á alimentação, brincadeiras e demais situações, e no que tange a uma resposta inadequada vinda da criança TEA, está mesma não deverá ser reforçada e nem punida (NASCIMENTO; SOUZA, 2018).

Outro fator encontrado na criança autista, principalmente na escola, é o desafio que elas impõem em aceitar regras estabelecidas pelos educadores e o espaço escolar, não aceitando serem contrariadas, bem como serem desobedientes, a não realização de atividades quando estão sem vontade e inibição em acatar ordens dos professores, o que condiz com a intervenção do psicopedagogo para ajudar a estabelecer de forma clara e simplista as regras, como: evitar conversar com a criança autista em seu momento de raiva, repetir as ordens da escola recompensando e elogiando quando o aluno exercer atos equivalentes com as demandas do educador e âmbito escolar, além de não deixar de reconhecer quando a criança realiza pequenos esforços para modificar a situação, mesmo que no momento não tenha muitos resultados, pois como é visto o processo de aprendizagem e educação da criança TEA é na maioria das vezes muito mais lento em comparação com outras crianças que não apresentem TEA (NASCIMENTO; SOUZA, 2018).

Objetiva-se conhecer cada aluno em sua singularidade de comportamentos e interesses para conseguir desenvolver maneiras de realizar uma conexão com as suas capacidades de aprender, tornando a aprendizagem algo interessante para este aluno autista de maneira menos frustrante por não 
aderir o ensino no estilo convencional que lhe é apresentado. Todas essas capacidades são adquiridas pelo psicopedagogo, após sua dedicação em conhecer a demanda e características que cada aluno TEA apresente (DINIZ; SANTOS, 2018). O psicopedagogo é capaz de compreender que apesar de todas as limitações que o aluno autista tenha, o mesmo é capaz de aprender e ter conhecimento, contudo ao seu tempo e de maneira distinta de outros alunos (DINIZ; SANTOS, 2018).

Ao considerar o processo de aprendizagem de forma ampla, não se pode deixar de mencionar o papel que a família reflete na vida da criança, investiga-se o comportamento e funcionamento familiar, o que contribuirá singularmente para levantar minuciosas hipóteses, colaborando para melhorar o desenvolvimento físico, psíquico e intelectual da criança (NASCIMENTO; SOUZA, 2018). A ampla visão e capacidades de trabalho do psicopedagogo favorecem em procedimentos como orientação para professores e família, até mesmo encaminhamentos para profissionais designados a trabalhar com a demanda que o aluno exige, pois o trabalho psicopedagogico envolve uma gama de maneiras e pessoas, não apenas ficando no paradigma de que só se deve trabalhar unicamente com o aluno autista (NASCIMENTO; SOUZA, 2018). É importante destacar o lugar do psicopedagogo no auxilio do diagnostico, pois o TEA em muitos casos é diagnosticado tardiamente, sendo na escola o lugar de observação de algum comprometimento da criança, como: lentidão e prejuízos na aprendizagem, até então não observados no contexto familiar, sendo assim o cuidado em compreender que o aluno possa estar com comprometimentos relativos a um transtorno, muitas vezes é impulsionado pelo psicopedagogo da escola ou da clínica, auxiliando no encaminhamento da criança para profissionais e assim posterior efetivar o diagnosticar de TEA (NASCIMENTO; SOUZA, 2018). Diagnostico que requer ainda mais a colaboração desse profissional, de forma a proporcionar para a família e escola oportunidades de entender melhor a criança autista e lidar com suas demandas sociais, fisiológicas, comportamentais e outras envolvidas (NASCIMENTO; SOUZA, 2018).

Como a relação social da criança com autismo é um tanto precária, e muitas delas não têm noções de regras e nem de limites, é preciso estabelecer essas regras e limites no trabalho com essas crianças, a fim de poder auxiliá-los a lidar com algumas dificuldades. Entretanto, ainda que o estabelecimento de regras claras seja útil, surge igualmente aprender como fazer amigos, entender os sentimentos e pensamentos das demais pessoas. Essas habilidades, com efeito, são aprendidas por meio de vivências e interação, porém aprender a interagir com outras pessoas é uma tarefa árdua para o autista, e o psicopedagogo pode promover meios para que isso aconteça. (BARON-COHEN, 1993, p. 38).

Na escola o psicopedagogo terá que conciliar as situações inesperadas que surgirão no processo de ensino aprendizagem do aluno autista, assim como os demais alunos com ou sem outros transtornos, trabalhando de maneira a aumentar as potencialidades e diminuindo o máximo de limitações (CARVALHO; CUZIN, 2008).

De acordo com Alves e Bossa (2017, p. 1), a Psicopedagogia é um campo no qual floresceu o conceito de sujeito autor. “[...] É uma área de estudo interdisciplinar que olha para o sujeito 
como um todo no contexto no qual está inserido, que estuda os caminhos do sujeito que aprende e apreende, adquire, elabora, saboreia e transforma em saber o conhecimento".

O psicopedagogo tem um papel de facilitador para a criança autista, nas questões sociais, linguagem e avaliações, mediando na interação social dela com outras crianças, nas atividades realizadas por ela, atividades sociais, ou seja, em cada situação que esse aluno autista necessite de auxílio para sua melhor convivência e aprendizagem (CARVALHO; CUZIN, 2008).

\begin{abstract}
Existem muitas condutas a serem adotadas frente à criança com TEA. A principal é acreditar que ela tem potencial para aprender, desde que seja oferecido o que é necessário para suas condições. Também é preciso saber que ela enxerga o mundo de uma forma diferente, que vive num mundo próprio. Alguns autistas conseguem se formar, constituir família e ter uma vida profissional independente. Há casos de autistas que nunca suspeitaram que o fossem. Por outro lado, devido à sua dificuldade em se comunicar, ou em verbalizar afeto, não conseguem, por vezes, manter um vínculo positivo com professores e colegas de sala de aula, apresentando um desempenho escolar insuficiente, aquém de suas possibilidades (CARVALHO; CUZIN p. 1581. 2008).
\end{abstract}

É imprescindível o papel de inclusão que o psicopedagogo realiza no ambiente escolar, uma vez que as características especificas do autismo, representam um afastamento social dos demais colegas, a incapacidade de um professor sozinho conseguir dedicar-se aos demais alunos de uma sala e dar atenção ao aluno autista e fornecer necessidades estratégicas distintas para o aluno TEA dos demais, se tratando de uma sala de aula com inúmeras crianças, dessa forma novamente é destacada a total importância do psicopedagogo no auxilio ao aluno TEA e até mesmo aos professores e família ocasionando assim melhores possibilidades para este aluno. (CARVALHO; CUZIN, 2008).

\title{
MÉTODO
}

A fim de atingir os objetivos ao qual se propõe esse estudo se utilizou como metodologia a pesquisa bibliográfica, para Lima e Mioto (2007, p. 38) "a pesquisa implica em um conjunto ordenado de procedimentos de busca por soluções, atento ao objeto de estudo, e que, por isso, não pode ser aleatório". Sendo assim esta foi feita a partir de leitura crítica e reflexiva dos materiais encontrados publicados em plataformas digitais.

Uma pesquisa exploratória, não sistemática, buscando torná-lo mais claro para construir hipóteses. A pesquisa é descritiva e explicativa, na qual se descreve os fatos e fenômenos de determinado contexto e justifica os fatores para a ocorrência dos fenômenos (GIL, 2007).

Este estudo foi realizado a partir de pesquisas em livros e bases de dados eletrônico como o SciELO. A busca por artigos e dissertações, utilizando os seguintes termos de busca: psicopedagogia no tratamento do aluno espectro autista. Foram encontrados treze trabalhos nos quais se utilizou oito para a realização do estudo. Como critérios de inclusão foram considerados: estar disposto na integra, 
contemplar o objetivo proposto e serem gratuitos. Como critério de exclusão desconsiderou-se artigos em língua estrangeira e que tivessem fora do objetivo do estudo.

A análise dos dados foi produzida na perspectiva da análise de conteúdo e está de acordo com Bardin (2009) A análise de conteúdo diz respeito ao estudo tanto dos conteúdos nas figuras de linguagem, reticências, entrelinhas, quanto dos manifestos, tornando-se um importante instrumento na condução da análise dos dados qualitativos, mas deve ser valorizado enquanto meio e de forma alguma pode ser confundido como finalidade em um trabalho científico. Dessa forma, inicialmente foi realizada uma leitura exploratória a fim de ter maior proximidade com os textos.

\section{RESULTADOS E DISCUSSÕES}

A proposta pedagógica em pesquisar sobre as peculiaridades do aluno com transtorno de espectro autista é demasiadamente nova e ganha o seu espaço desde as políticas que aludem o contexto de aprendizagem das crianças TEA no ambiente escolar, articulando com outra profissão relativamente nova em comparação com demais profissões, porém não menos importante, no mais reconhecendo o seu espaço de trabalho e total importância, nas disfunções da aprendizagem. Articulando o psicopedagogo com o aluno TEA, trouxe o propósito de realçar a função e significado que esse profissional exerce e adquire seu espaço na educação. O trabalho com o autista é minucioso e envolvente, precisando de um profissional capaz para compreender todos os estágios e processos do transtorno, sabendo solucionar e minimizar as urgentes disparidades que proporcionam ainda mais o atraso do aluno TEA do convívio social e aprendizado escolar.

O psicopedagogo vem com uma bagagem de formação em graduações que por si só que favorecem o desenvolvimento sadio de crianças com déficits e posterior da graduação é salientado com mais conhecimento ao dedicar-se a uma especialização em psicopedagogia, cooperando ainda mais para abrir caminhos e desmembrar barreiras, como no caso das especificidades que o Transtorno de Espectro Autista - TEA trás por si só a criança.

Técnicas e entendimento para trabalhar com autistas florescem as potencialidades que até então não eram percebidas. O psicopedagogo auxilia no desenvolvimento pessoal e futuro do aluno, trazendo a tona capacidades que antes se tornavam distantes do real. O conceito do presente projeto foi de apresentar a relevância do acompanhamento e função do psicopedagogo no contexto escolar, bem como solucionar alguns percalços referentes ao ensino escolar ao aluno autista, dentre outros que o psicopedagogo colabora também na manutenção como: o enfrentamento dos problemas da família perante a criança TEA e o processo de inclusão social, pois o aluno adquirindo níveis de habilidades tanto comportamentais quanto intelectual, aumenta-se o processo de inclusão para com o corpo escolar, familiar e social. 


\section{REFERÊNCIAS}

ALVES, M. D. F, BOSSA, N. Psicopedagogia: em busca do sujeito autor. Disponível em: https://bit.ly/ 3oJcYF9. Acesso em: 02 de jul. de 2017.

BARDIN, L. Análise de Conteúdo. São Paulo: Martins Fontes, 2009.

BARON-COHEN, S.; LESLIE, A. M.; FRITH, U. Does the autistic child have a 'theory of mind'? Cognition, n. 21, p. 37-46, 1993.

BATISTA, T. N. VIEIRA, D, O. Psicopedagogia e inclusão: desafios na reinserção de aluno autista em classe regular de ensino. Instituto de Psicologia - Departamento de Psicologia Escolar e do Desenvolvimento - PED, p. 1-50. Brasília, 2015.

CARVALHO, E. G. A; CUZIN, M. I. (orgs). Psicopedagogia institucional e sua atuação no mercado de trabalho. Campinas. FE/UNICAMP, 2008.

DINIZ, C. N.; SANTOS, M. P. A inclusão dos usuários com transtorno de espectro autista pela prática do letramento informacional na biblioteca escolar. Revista ACB. n 1, v. 23, p. 92-106. 2018.

GIL, A. C. Como elaborar projetos de pesquisa. 4. ed. São Paulo: Attlas, 2007.

LIMA, T. C. S. de; MIOTO, R. C. T. Procedimentos metodológicos na construção do conhecimento científico: a pesquisa bibliográfica. Katálysis, v. 10, n. esp. , p. 37-45, 2007. Disponível em: https:// bit.ly/31VUjnv. Acesso em: 25 out. 2019.

NASCIMENTO, G. A. SOUZA, S. F. A inclusão de alunos com Transtorno do Espectro Autista (TEA): possibilidades de intervenção psicopedagógica através da Análise do Comportamento Aplicada. Paidéia r. do cur. de ped. da Fac. de Ci. Hum., Soc. e da Saúde, Belo Horizonte, n. 19, v. 13, p. 163-185, 2018.

PATTO, M. H. A produção do Fracasso escolar. São Paulo: Casa do Psicólogo, 1990.

PERES, M, R. Psicopedagogia: Aspectos históricos e desafios atuais. Revista de educação. Campinas, n. 5, v. 3, p. 41-45, nov. 1998.

SILVA, A. B. B; GAIATO, M. B.; REVELES, L. T. Mundo singular: entenda o autismo. Objetiva. Rio de Janeiro, 2012. 